\section{Military Technical College Kobry El-Kobbah, Cairo, Egypt.}

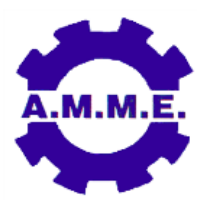

\title{
BALLISTIC IMPACT RESPONSE OF AN ALUMINUM SANDWICH PANEL WITH AUXETIC HONEYCOMB CORE STRUCTURE
}

\author{
R. A.Mohamed ${ }^{*}$ S. M. Lawaty ${ }^{\dagger}$, A. M. El-Butch $¥$
}

\begin{abstract}
Aluminum Metallic sandwich structures with auxetic core are found to be good energy absorbers for impact. The ballistic performance of honeycomb sandwich panels (HSPs) subjected to in-plane projectile impact has been studied by means of explicit dynamic nonlinear finite element simulations. The HSPs, under investigation, consist of two identical aluminum alloy face-sheets and an aluminum honeycomb core featuring two types of unit cell configurations, namely, regular and re-entrant hexagons. In modeling, the effects of several parameters like impact velocity, length, thickness and angle of the unit cell ribs, on the ballistic limit and energy absorption of the auxetic core panels during perforation are discussed in detail. Impact ballistic tests were also carried out and the results were compared with that of the theoretical finite element model. It has been found that HSPs with re-entrant auxetic honeycomb core has better ballistic resistance than regular ones, due to the negative Poisson's ratio effect of the core. The geometric parameters have shown non-monotonic effects on the panel's ballistic capacities.
\end{abstract}

\section{KEY WORDS:}

Ballistic impact; Auxetic honeycomb; Sandwich panels; High impact velocity.

Assistant Lecturer, Faculty of Engineering, Mataria, Helwan University, Cairo, rmdan abdelhamed2000@yahoo.com.

$\dagger$ Assistant Professor, Faculty of Engineering, Mataria, Helwan University, Cairo, samylawaty@m-eng.helwan.edu.eg.

₹ Professor, Faculty of Engineering, Mataria, Helwan University, Cairo, elbutch@aucegypt.edu. 


\section{NOMENCLATURE}

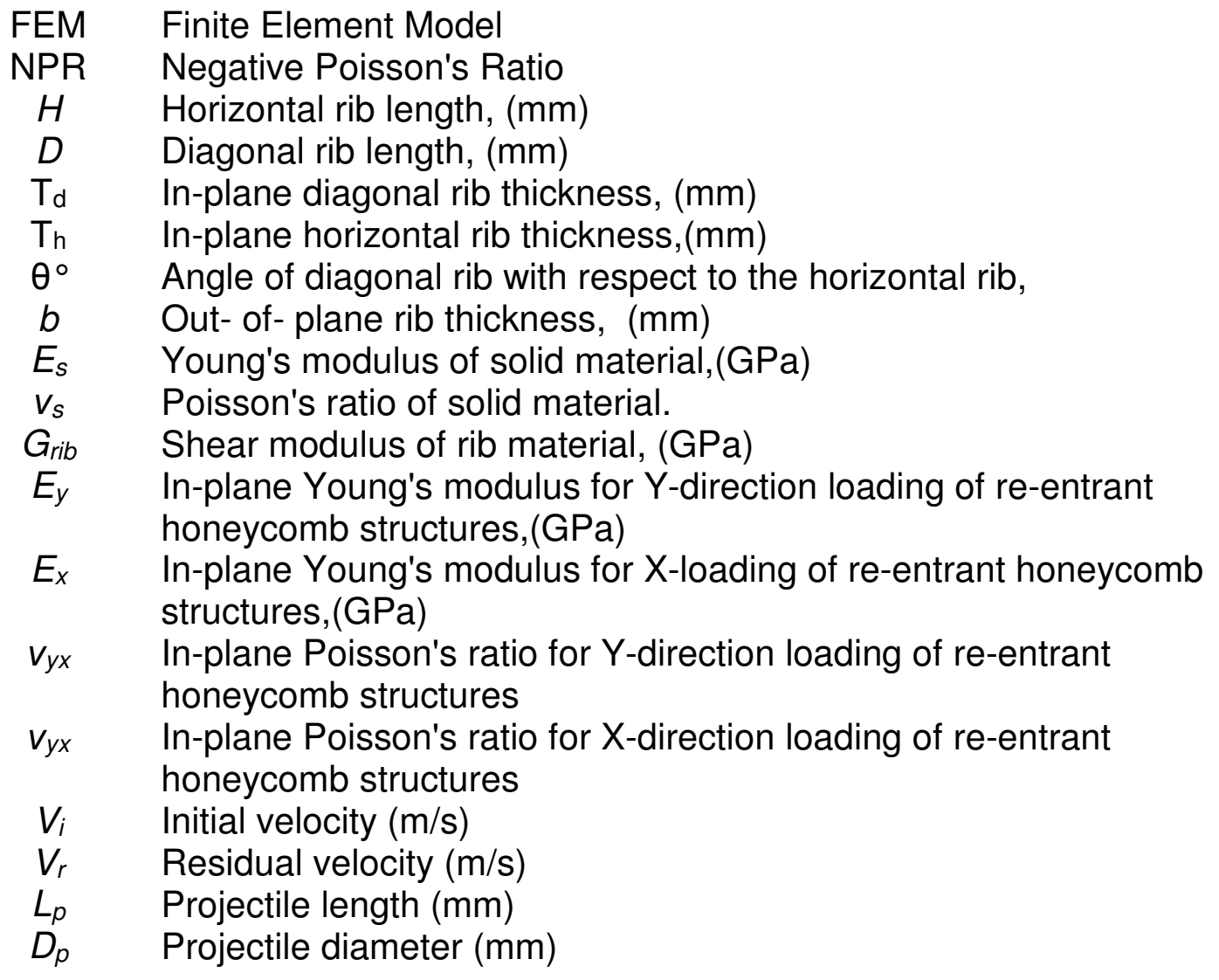

\section{INTRODUCTION}

As a novel composite structure, a sandwich panels with cellular core (frequently metallic foams) have been widely used as weight-efficient components and excellent energy dissipating structure, and thus can be used as an energy absorber in a wide range of applications under extreme loading conditions such as ballistic impact.

The impact behavior of a sandwich panel depends on many factors, not only the mechanical properties of its constituents, skins and core, but also the adhesive capacity of the skin-core interface. This high-velocity impact behavior differs from the low-velocity one, and therefore the conclusions drawn in studies on low-velocity impacts are not applicable to high-velocity cases. In this way, a high-velocity impact is a phenomenon controlled by wave propagation, and is essentially independent of boundary conditions, whereas a low-velocity impact is highly influenced by the boundary conditions [1].

Most studies on high-velocity impact behavior of sandwich structures are based on experimental tests [2-3]. Although experimental studies provide information on the sandwich structure tested, since impact phenomena depend on numerous parameters, knowledge of its influence on ballistic behavior requires abroad test program, which is time consuming and expensive. To reduce the cost and time, it is essential to use theoretical modeling. The most widely models used to analyze the perforation of sandwich structures are analytical models [4] and numerical codes [5]. The main 
advantage of finite element models is the quick analysis of the influence of different parameters on behavior of the sandwich armor.

Ballistic impact with emphasis on spherical strikers which provide more in plane damage was investigated by Goldsmith and Louie [6]. An analytical model was proposed for perforation of sandwich panels with honeycomb core by W. Hou and $F$. Zhu et. al. [7]. Investigations into the ballistic loading on composite structures have been extensively conducted on polymer and glass/carbon fabric based laminates [4,6,8 -11], and comparably less attention has been paid on sandwich structures.

Most of the existing work on sandwich panels has focused on structures with conventional honeycomb or PVC foam cores. Goldsmith and Sackman [10] tested the effects of several parameters, e.g. impact velocity, boundary conditions and bonding strength between the honeycomb core and aluminum faces, on the energy dissipation during perforation. Mines et al. [12] examined the low velocity perforation behavior of sandwich panels with polymeric composite skins and honeycomb core.

Some damages that may seriuosly affect important components are sandwich type vehicle armor could be impacted by bullets or blast debris. In another case, jet engine nacelles may be subjected to impact by birds, hailstones and runaway debris. Depending on the impact energy, the resulting damage to the honeycomb sandwich panels (HSPs) ranges from face-sheet indentation to complete perforation. One important parameter to describe a structure's ability to withstand projectile impact is its ballistic limit, which is defined as the maximum projectile impact velocity that a structure can withstand without being perforated [13]. Therefore, the study of ballistic behavior of the HSPs is a critical demand of advanced industries.

Substantial efforts have been devoted to the projectile impact behavior of metallic honeycomb panels through experimental [7,10,14], analytical [15-16] and numerical methods [16]. Numerical methods, typically the finite element analysis (FEA), have been employed by some researchers to study in depth the perforation process of HSPs subjected to low-velocity [16] and high-velocity [17] projectiles.

The present study investigates the ballistic resistance of the honeycomb sandwich panels (HSPs), when subjected to high-velocity in-plane projectile impact using FEM, as well as illustrates the effects of the cellular geometry parameters such as cell rib length, thickness and angle on the ballistic behavior of honeycomb structures. In addition, experimental tests have been conducted to assess the finite element model results. Certain goal of this study is design information for such panel to be employed as armor against ballistic impact loads.

\section{FINITE ELEMENT MODELING}

The finite element model used to analyze the projectile impact into HSPs has been implemented in ANSYS/Explicit Dynamic [18]. The influence of boundary conditions have slight effect in high-velocity impacts. The 3D FEM normally includes two solids: a projectile and a sandwich panel. Because plastic deformation is found in the projectile after the ballistic test, elasto-plastic behavior model represents the steel projectile material. The sandwich panel consists of two identical aluminum face sheet skins and an aluminum auxetic and regular honeycomb core as shown in Fig. (1). 


\section{Material Properties and Modeling}

\section{Projectile and aluminum face-sheets}

As the focus of this work is the sandwich panel, the projectile was assumed to behave as an elasto-plastic material in ANSYS/Explicit Dynamic with a Young's modulus of $210 \mathrm{GPa}$ and a Poisson's ratio of 0.3 . The face-sheets of the panels are made of aluminum alloy AA 6xxx series with the following mechanical properties: mass density $\rho=2700 \mathrm{~kg} / \mathrm{m}^{3}$, Young's modulus $E=70 \mathrm{GPa}$, and Poisson's ratio $=0.29$. An elastoplastic material model represented the properties of face-sheets.

\section{Core Material}

The material of the honeycomb cores is assumed the same as that of the face-sheets, which is aluminum alloy AA 6xxx series. The mechanical properties of the base material are estimated from the results of the tensile tests.

\section{Geometry Modeling}

The explicit dynamics simulation has some parameters that have to be firstly studied for stability of the results. Such parameters are the end time and the mesh element size. The end time has selected to assure that it is sufficient for high velocity impact simulation process, where projectile can penetrate the structure or rebound. It has been found that $10 \mathrm{e}-3 \mathrm{~s}$ is sufficient for complete simulation process. In addition, the characteristic mesh size of $0.3 \mathrm{~mm}$ is satisfying the convergence and numerical stability requirements for the HSP structure. The element type is solid beam189. Initial and boundary conditions are fed to the finite element model to be matched with the case study.

\section{EXPERIMENTAL WORK}

To validate the finite element model results, a high-velocity impact test has been carried out on specimen of $190 \mathrm{~mm}$ in length, $130 \mathrm{~mm}$ in width, and $50 \mathrm{~mm}$ in thickness. The test is performed using a ballistic rifle. The specimens were impacted by $7.62 \times 39$ $\mathrm{mm}$ armor piercing projectile. The projectile has $840 \mathrm{~m} / \mathrm{s}$ impact velocity and far $12 \mathrm{~m}$ from the target mount. The experimental facilities and equipment of the department of Weapons and Ammunition, M.T.C., are used for performing these tests. Ballistic test measurements, post-firing examinations and test procedures are the same as that performed by Abdelwahed et. al [14]. Figure (2) shows the scheme of the used ballistic setup.

In the test, re-entrant honeycomb specimen is fabricated by using wire-cutting machine. It is glued to two $1 \mathrm{~mm}$ faceplates from aluminum AA 6xxx series at left and right sides, as shown in Fig (3). The geometrical parameters of the re-entrant honeycomb are $\left(H=40 \mathrm{~mm}, \mathrm{D}=25 \mathrm{~mm}, \mathrm{Th}=\mathrm{Td}=10 \mathrm{~mm}, \mathrm{~b}=50 \mathrm{~mm}, \theta=75^{\circ}\right)$. 


\section{RESULTS AND DISCUSSIONS}

\section{Validation of Finite Element Model}

The numerical results have been compared with the experimental ones to validate the finite element model. The variables selected to validate the numerical model were the residual velocity, and the perforation depth. The projectile stops into the target after penetrating the first rib thickness and a part of the second rib thickness; the measured depth is $40 \mathrm{~mm}$ whereas, the predicted depth is $40.825 \mathrm{~mm}$. It is obvious that the obtained results from the experimental work and simulations using ANSYS14 have a good agreement as depicted in Fig (4).

\section{Effect of Honeycomb Cell Type on Projectile Velocity}

It is of special interest to investigate the influence of cell configuration of the honeycomb core, i.e. regular and auxetic hexagons, on the ballistic resistance of the entire sandwich panel. FE simulations were run for the two types of HSPs subjected to projectile impact velocity of $300 \mathrm{~m} / \mathrm{s}$. Figure (5) plots the predicted time histories of projectiles velocity during the penetration of the regular and auxetic HSP at $V_{i}=300$ $\mathrm{m} / \mathrm{s}$, respectively.

At time $0.175 \mathrm{e}-3 \mathrm{~s}$, it is seen from the figure that the projectile losses its velocity during the perforation of the auxetic HSP more faster than that in regular structure. It means that the auxetic HSP is better in damping the projectile velocity than the regular HSP.

\section{Effect of Rib Angle on Projectile Velocity}

Figures (6) and (7) show the projectile velocity-time histories for the auxetic HSP's with different cell rib angles at $V_{i}=650 \mathrm{~m} / \mathrm{s}$ in $Y$ and $X$ directions, respectively. It is seen from the figures that the projectile residual velocity increases as it increasing the rib angle. It means that the ability of auxetic HSP to absorb the kinetic energy of projectile will reduce. With respect to $\mathrm{Y}$-direction, the model predicts that the projectile stops in the structure at time $6.5 \mathrm{e}-4 \mathrm{~s}$ at rib angle of $75^{\circ}$ while it stops at time $7.8 \mathrm{e}-4 \mathrm{~s}$ for rib angle of $79^{\circ}$ and at $1.1 \mathrm{e}-3 \mathrm{~s}$ for rib angle of $83^{\circ}$.

With respect to X-direction, the model predicts that the projectile stops in the structure at time $5 \mathrm{e}-4 \mathrm{~s}$ for rib angle of $75^{\circ}$ while it stops at time $6 \mathrm{e}-4 \mathrm{~s}$ for rib angle of $79^{\circ}$ and at $8 \mathrm{e}-4 \mathrm{~s}$ for rib angle of $83^{\circ}$.

Decreasing the rib angle increases the flexural and hinging of diagonal ribs that leads to high densification of auxetic honeycomb structure against the projectile velocity. Therefore, the auxetic HSPs with small rib angle have good ballistic capacity.

It is found that X-direction is better than $Y$-direction in absorbing the projectile's energy, as shown in Fig. (8). This is due to that in $X$ - direction the Projectile hit the inclined diagonal rib, making it change its direction and thus loses much of its kinetic energy in different paths without penetrating. 


\section{Effect of Horizontal Rib Thickness on Projectile Velocity}

Figures (9) and (10) show the projectile velocity-time histories when penetrating the auxetic HSPs with different horizontal rib thicknesses of $Y$ and $X$ directions, respectively, at $V_{i}=650 \mathrm{~m} / \mathrm{s}$. It is seen from the figures that increasing the cell horizontal rib thickness decreases the projectile velocity during its perforation into the HSP. It means that the structure with highest horizontal rib thickness much efficient in absorbing the projectile energy at the respective impact velocity. An explanation for such response of the auxetic HSP to unit cell rib thickness variation is proposed. With a large rib thickness, the stiffness of the auxetic HSP becomes much higher, so the penetration process becomes much more difficult.

Figure (11) shows the projectile has been rebounded at time 5e-4 s during impacting in $\mathrm{X}$ direction, while for $\mathrm{Y}$ direction the projectile has been penetrated. The explanation of such phenomena like that discussed in the rib angle variation.

\section{Effect of Diagonal Rib Thickness on Projectile Velocity}

Figures (12) and (13) plots the projectile velocity-time histories during its penetration into the HSP structure at different cell diagonal rib thicknesses at $V_{i}=650 \mathrm{~m} / \mathrm{s}$. Similar trends to the effect of horizontal rib thickness on the projectile velocity-time histories are predicted, the increase in the diagonal thickness leads to a decrease in the projectile velocity. In addition, $X$ direction is better than $Y$ direction in absorbing the projectile velocity as depicted in figure (14).

\section{CONCLUSION}

In the present work, the penetration of composite sandwich panels subjected to highvelocity impact has been analyzed using a three dimensional finite element model implemented in ANSYS14/Explicit Dynamics. In addition, experimental impact test was carried out to assess results of the numerical model.

- Good agreement has been found between numerical and experimental results

- Re-entrant honeycomb cell types have better ballistic resistance than traditional honeycomb cell types.

- Increasing cell rib angle while decreasing cell rib thicknesses leads to an increase in the velocity of the projectile.

- The energy absorption mechanism in the core is due to the plastic deformation of the aluminum wall and the damage is found to be localized in a small area around the impact point.

\section{REFERENCES}

[1] B. L. Buitrago, C. Santiuste, S. Sánchez-Sáez, E. Barbero, and C. Navarro, "Modelling of composite sandwich structures with honeycomb core subjected to high-velocity impact", Compos. Struct., vol. 92, no. 9, pp. 2090-2096, 2010.

[2] C. W. Villanueva, "The high velocity impact response of composite and FMLreinforced sandwich structures", Compos Sci Technol, vol. 64, pp. 35-54, 2004. 
[3] M. B. Vaidya, S. Nelson and B. Sinn, "Processing and high strain rate impact response of multi-functional sandwich composites", Compos Struct, vol. 429, pp. 40-52, 2001.

[4] F. L. Icardi, "Impact analysis of sandwich composites based on a refined plate element with strain energy updating", Compos Struct, vol. 89, pp. 35-51, 2009.

[5] R. W. Ryan and S. Schaefer, "Numerical simulation of hyper velocity impact on CFRPAI HC SP space craft structures causing penetration and fragment ejection", Compos Struct, vol. 703, pp. 12-33, 2006.

[6] L. D. Goldsmith, "Axial perforation of aluminum honeycombs by projectiles", Int J Solids Struct, Vol 32, pp. 1017-1046, 1995.

[7] F. D. Hou, F. Zhu and G. Lu, "Ballistic impact experiments of metallic sandwich panels with aluminium foam core", Int. J. Impact Eng, vol. 47, pp. 1045-1055, 2010.

[8] G. Caprino, V. Lopresto, and D. Santoro, "Ballistic impact behaviour of stitched graphite / epoxy laminates", Int. J. Impact Eng, vol. 67, pp. 325-335, 2007.

[9] D. R. Christman and J. W. Gehring, "Analysis of high velocity projectile penetration mechanics", Int. J. Appl. Phys., vol. 37, pp. 259-265, 1966.

[10] W. Goldsmith and J. L. Sackman, "An experimental study of energy absorption in impact on sandwich plates", Int. J. Impact Eng, vol. 12, no. 2, pp. 241-262, 1992.

[11] S. W. Lee and C. Sun, "Dynamic penetration of graphite/epoxy laminates impacted by ablunt ended projectile", Compos. Sci. Technol., vol. 49, pp. 369380, 1993.

[12] R. A. W. Mines, C. M. Worrall, and A. G. Gibson, "Low velocity perforation behaviour of polymer composite sandwich panels", Int. J. Impact Eng., vol. 21, no. 10, pp. 855-879, 1998.

[13] W. Goldsmith, G. T. Wang, K. Li, and D. Crane, "Perforation of cellular sandwich plates", Int. J. Impact Eng., vol. 19, no. 5, pp. 361-379, 1997.

[14] M. A. Abdel-Wahed, A. M. Riad, A. M. Salem and A. S. Zidan, "Penetration of a small caliber projectile into single and multi-layered", Eur. Conf. Comput. Mech., vol. 10, pp. 1-8, 2010.

[15] C. C. Foo, G. B. Chai, and L. K. Seah, "A model to predict low-velocity impact response and damage in sandwich composites", Compos. Sci. Technol., vol. 68, no. 6 , pp. 1348-1356, 2008.

[16] C. C. Foo, L. K. Seah, and G. B. Chai, "Low-velocity impact failure of aluminium honeycomb sandwich panels", Compos. Struct., vol. 85, no. 1, pp. 20-28, 2008.

[17] K. Miljkovi, A. P. Jones, and M. C. Price, "High velocity impact modelling of ice into ice: application to outer solar system landers and penetrators", Eur. Planetary Sci. Cong., vol. 5, pp. 321-322, 2010.

[18] ANSYS_ Academic Research, Release 14.0, Help System, Elements Reference, solid beam 189. ANSYS, Inc., USA, 2013. 


\section{Tables and Figures}

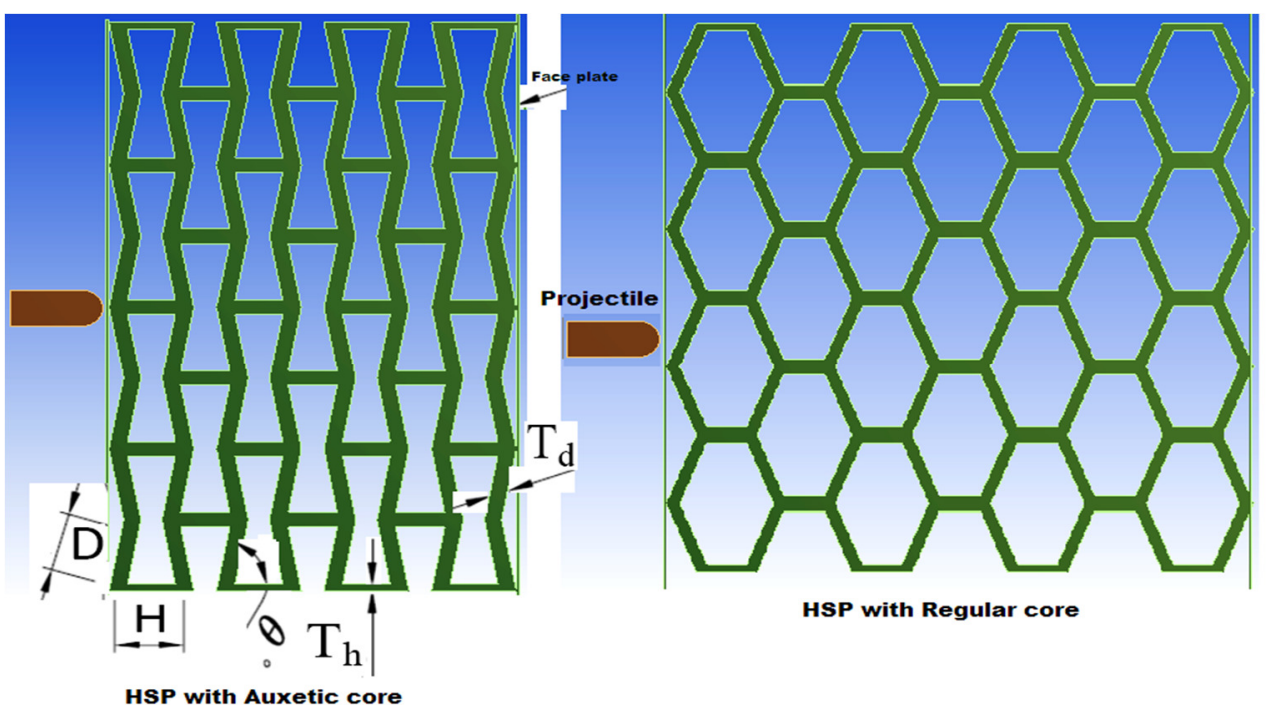

Figure (1). Layout of the geometrical parameters for the HSP with auxetic and regular core.

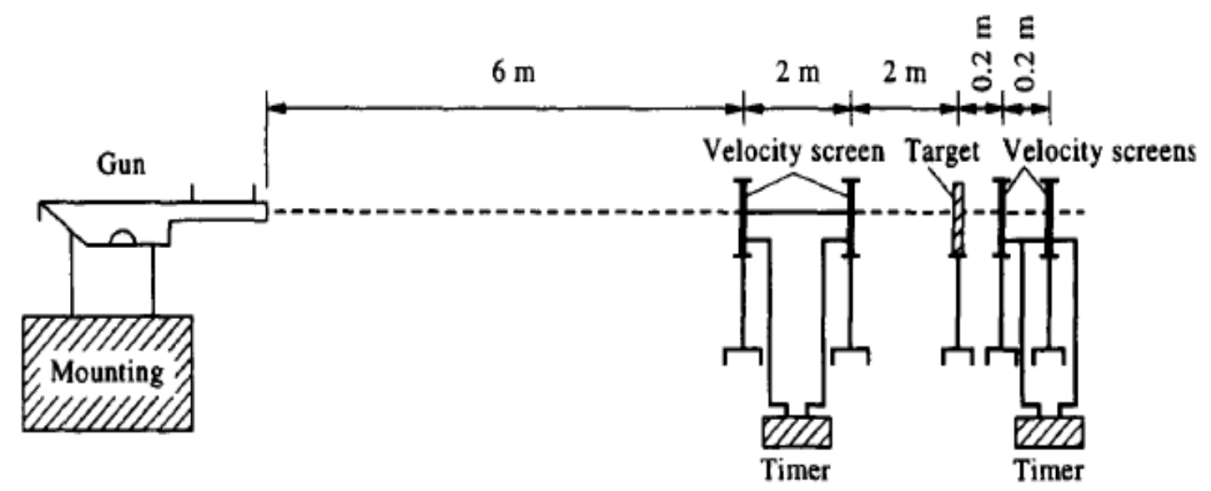

Figure (2). Schematic of the used ballistic setup.

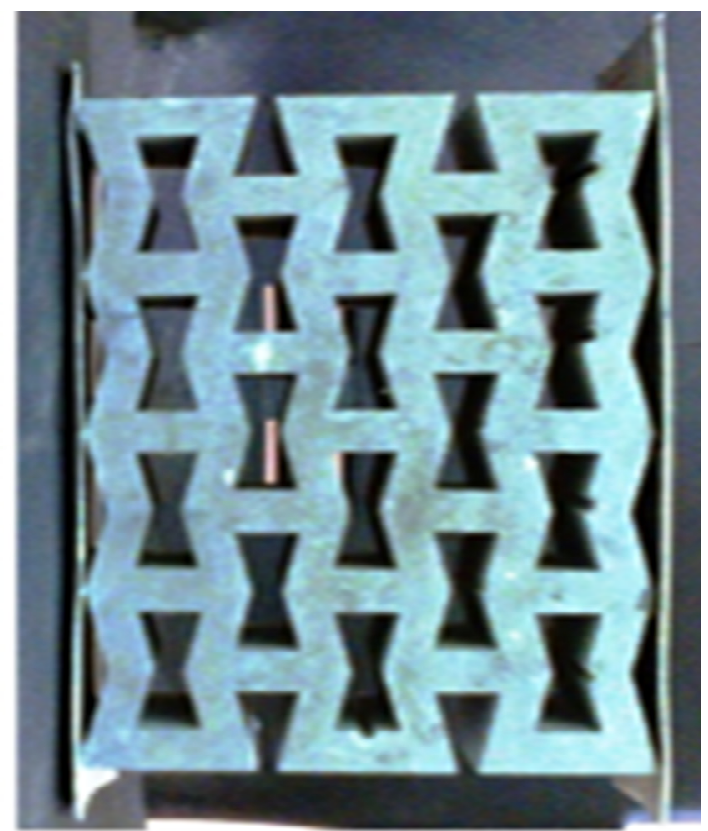

Figure (3). HSP fabricated by using wire-cutting machines. 

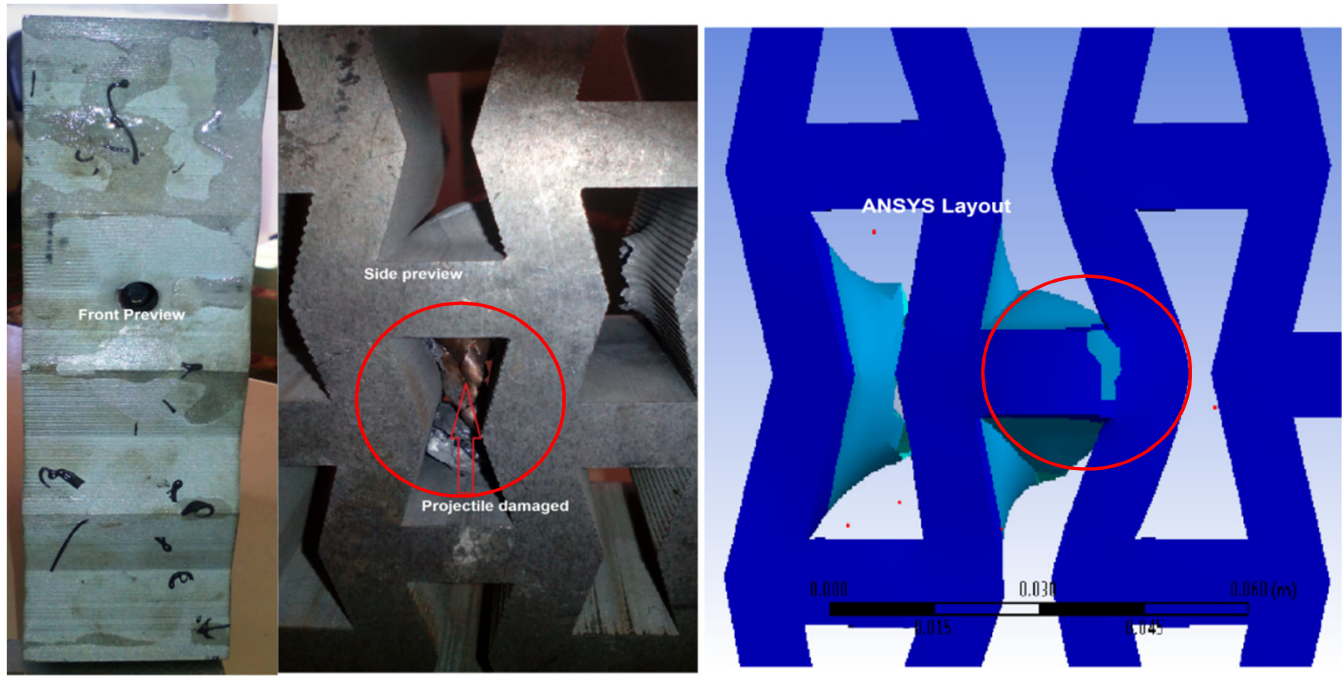

Figure (4). Comparison between experimental result and FEA.

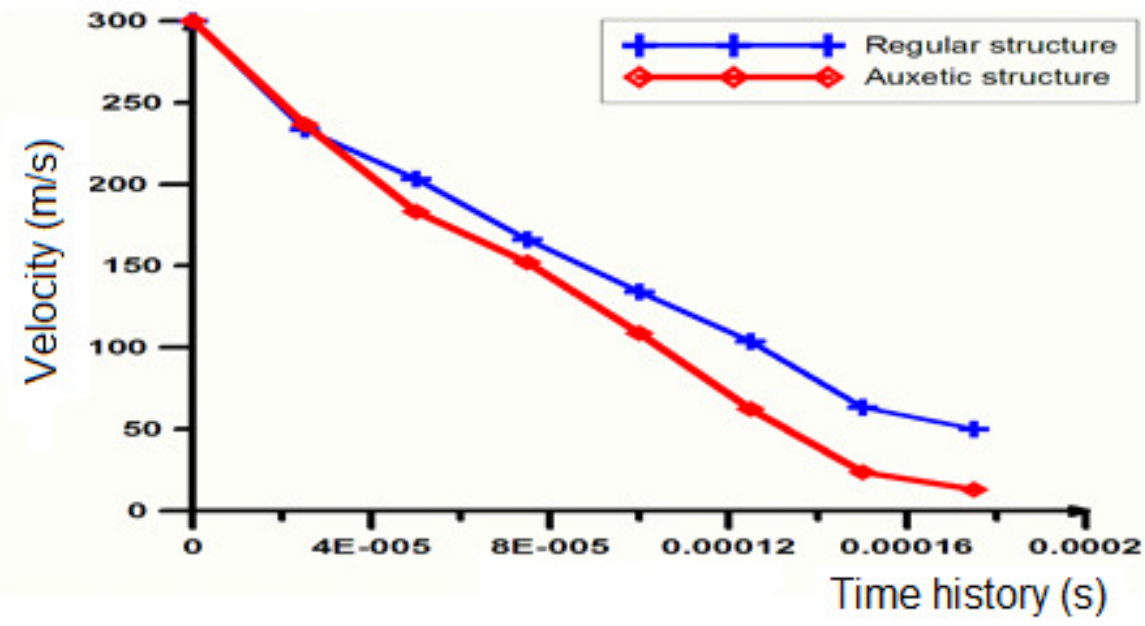

Figure (5). Comparison between the projectile velocity of the auxetic and regular

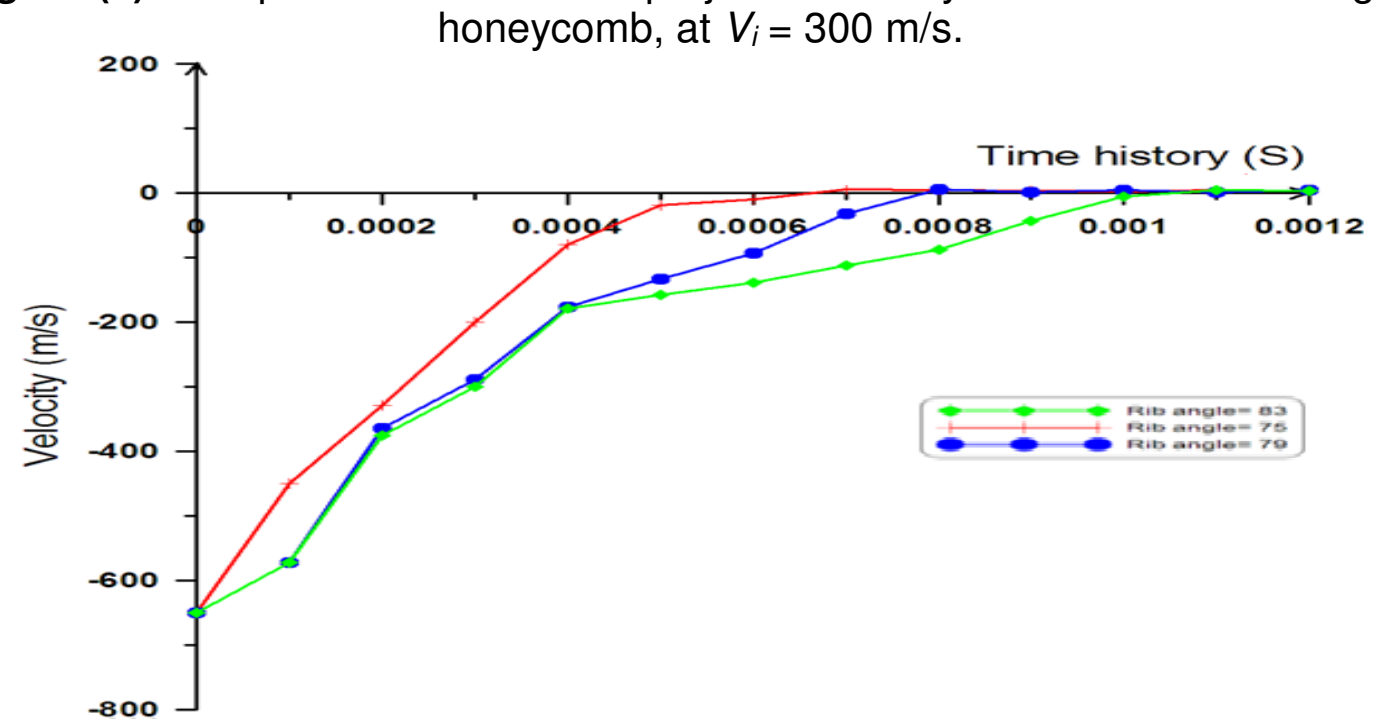

Figure (6). Predicted projectile velocity - time history at $V_{i}=650 \mathrm{~m} / \mathrm{s}$ in Y-direction for different cell rib angle. 


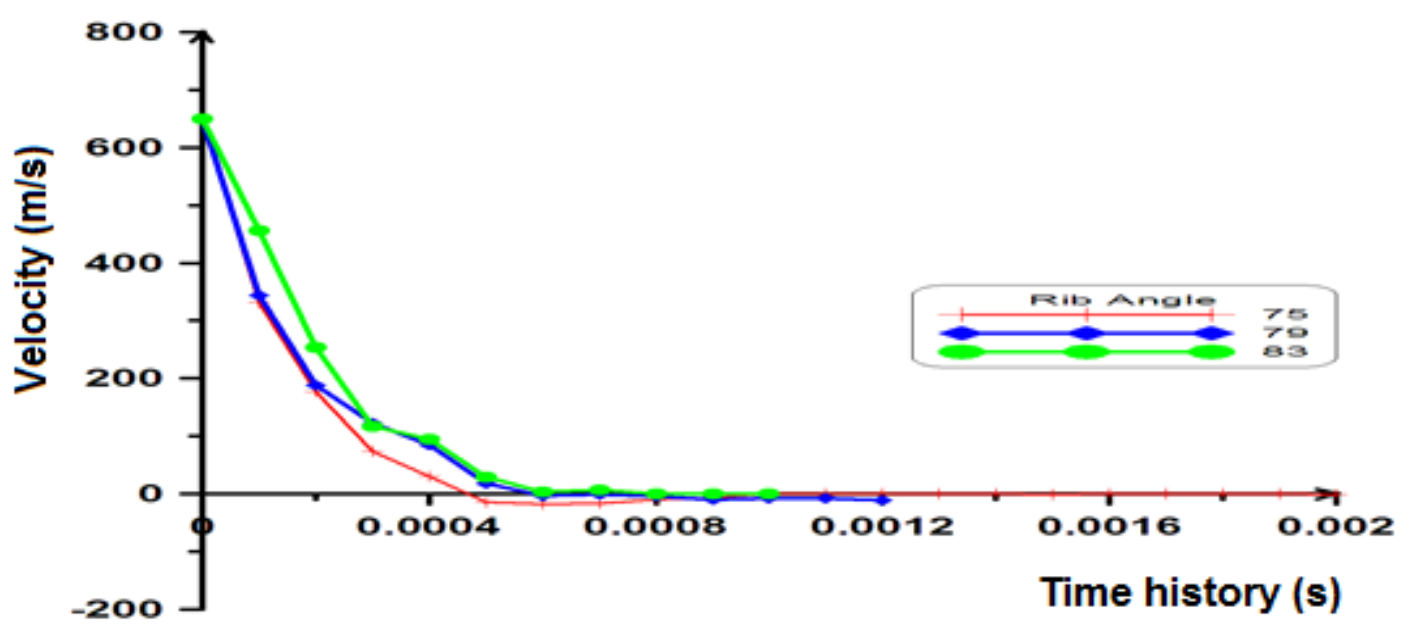

Figure (7). Predicted projectile velocity - time history at $V_{i}=650 \mathrm{~m} / \mathrm{s}$ in X-direction for different cell rib angle

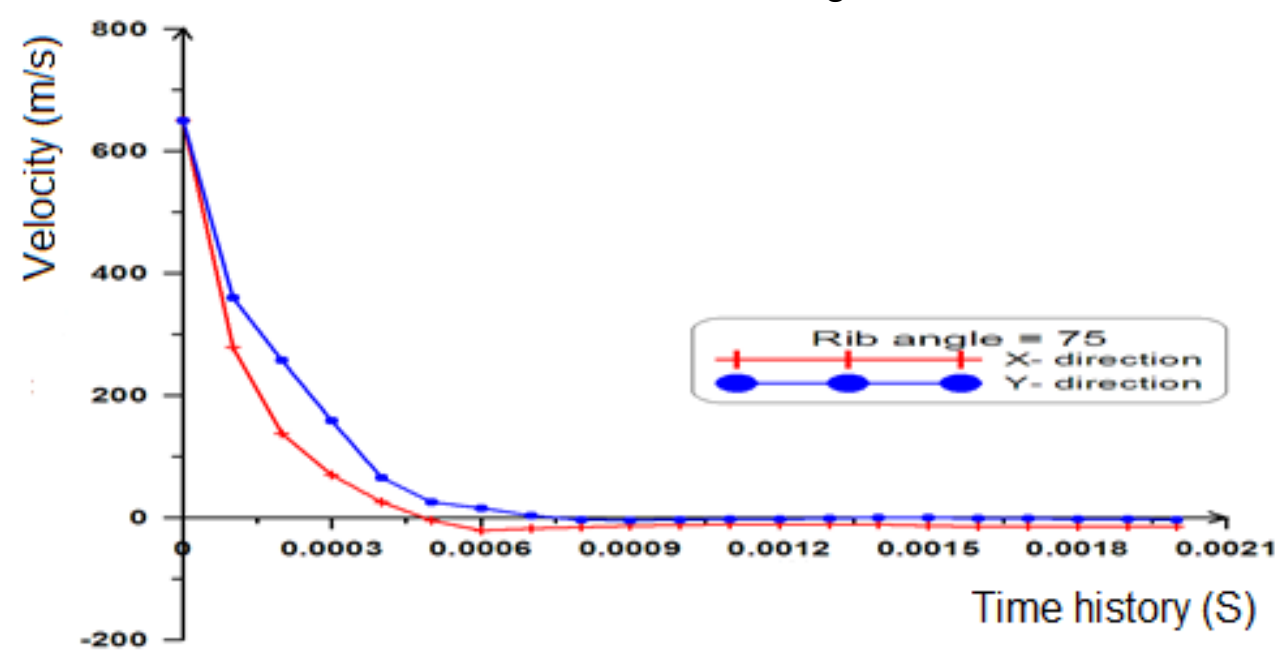

Figure (8). Comparison between the projectile velocities in $X \& Y$ directions, at $\theta=$ $75^{\circ}$.

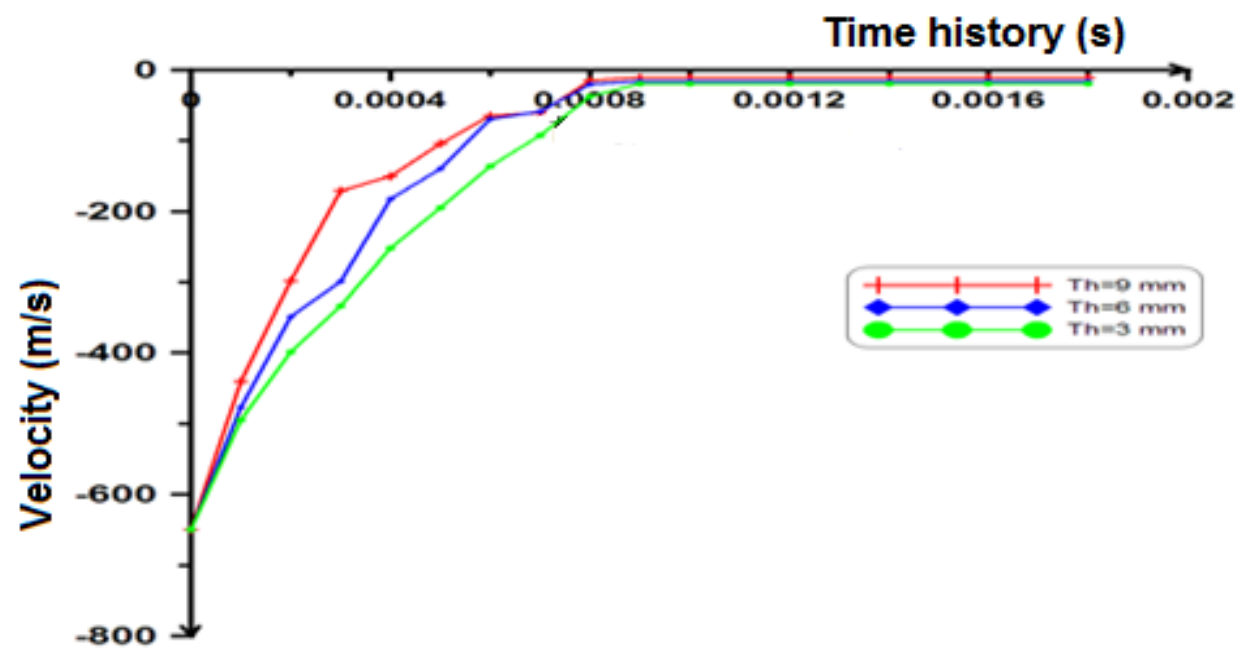

Figure (9). Predicted projectile velocity - time history at $V_{i}=650 \mathrm{~m} / \mathrm{s}$ in Y-direction for different cell horizontal rib thickness, $\left(T_{h}\right)$. 


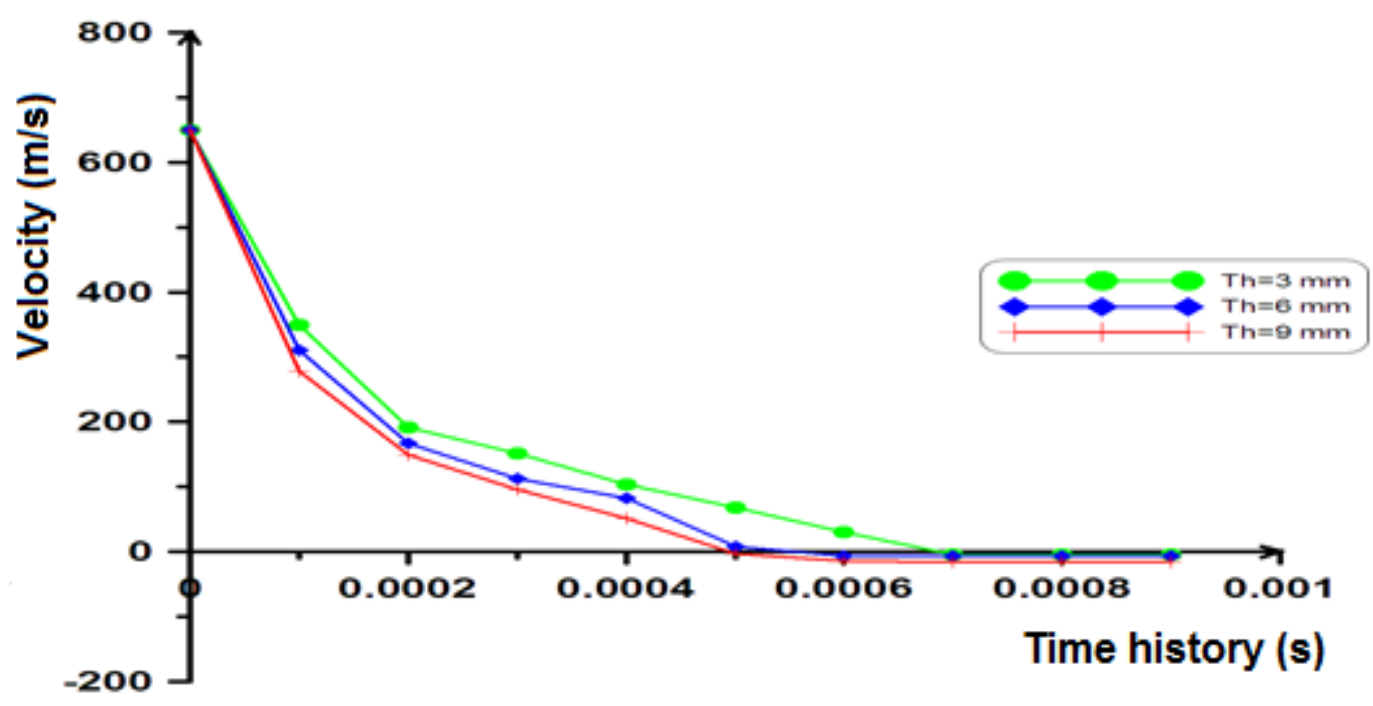

Figure (10). Predicted projectile velocity - time history at $V_{i}=650 \mathrm{~m} / \mathrm{s}$ in X-direction for different cell horizontal rib thickness, $\left(T_{h}\right)$.

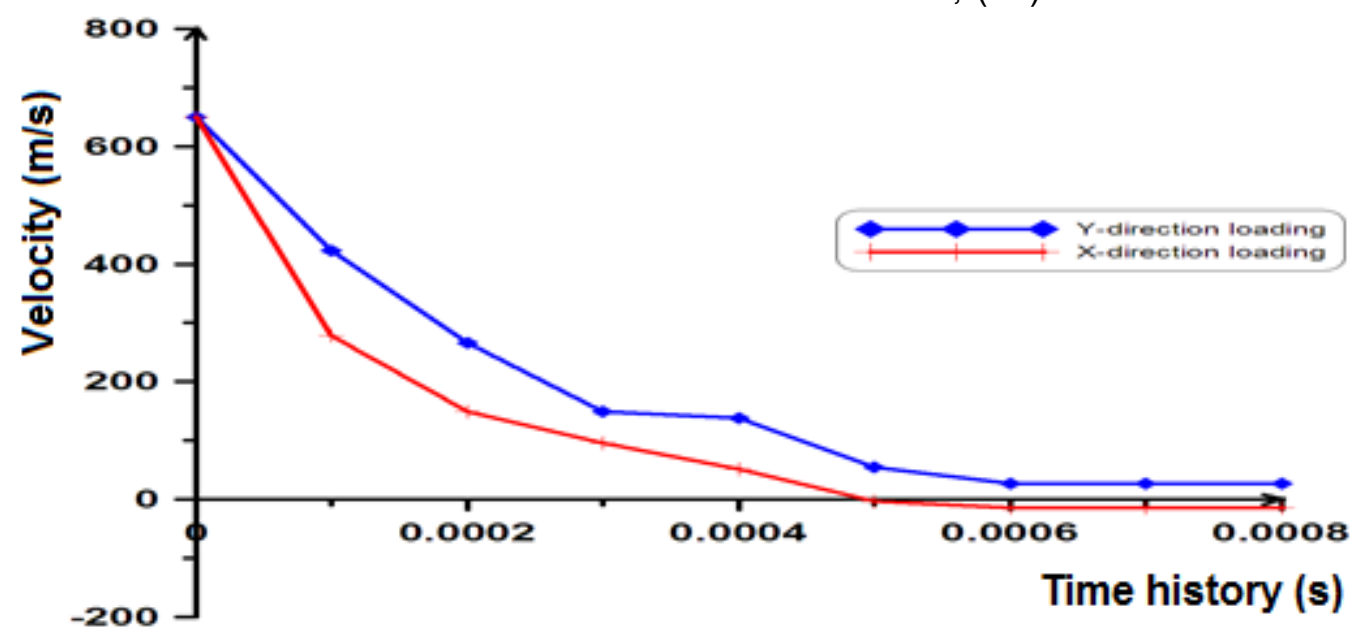

Figure (11). Comparison between the projectile velocities in $X \& Y$ directions, at $T_{h}=9$ $\mathrm{mm}, V_{i}=650 \mathrm{~m} / \mathrm{s}$.

Time history(s)

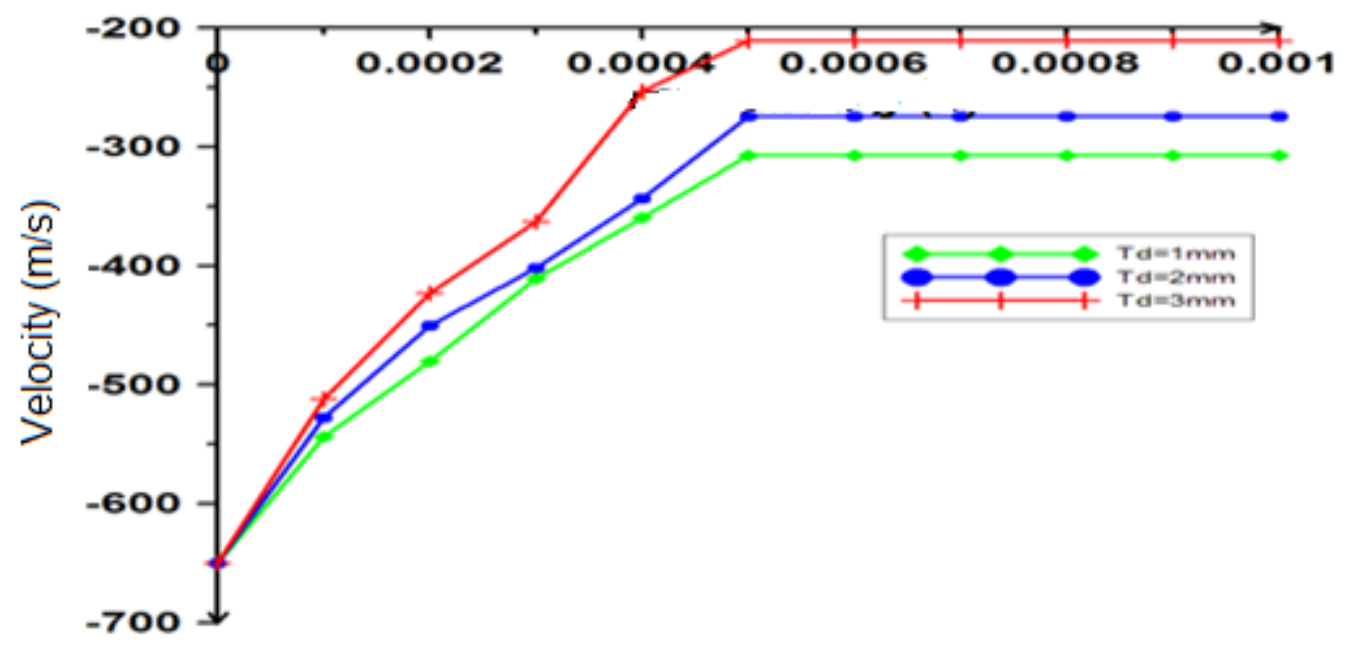

Figure (12). Predicted projectile velocity - time history at $V_{i}=650 \mathrm{~m} / \mathrm{s}$ in Y-direction for different cell diagonal rib thickness, $\left(T_{d}\right)$. 


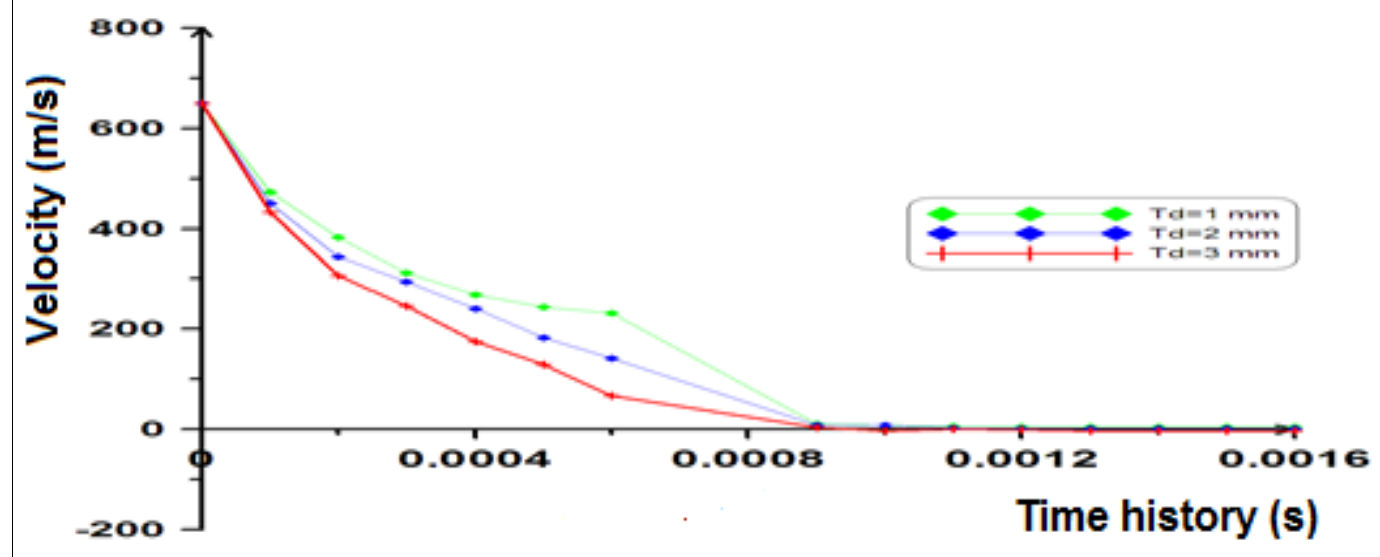

Figure (13). Predicted projectile velocity - time history at $V_{i}=650 \mathrm{~m} / \mathrm{s}$ in X-direction for different cell diagonal rib thickness, $\left(T_{d}\right)$.

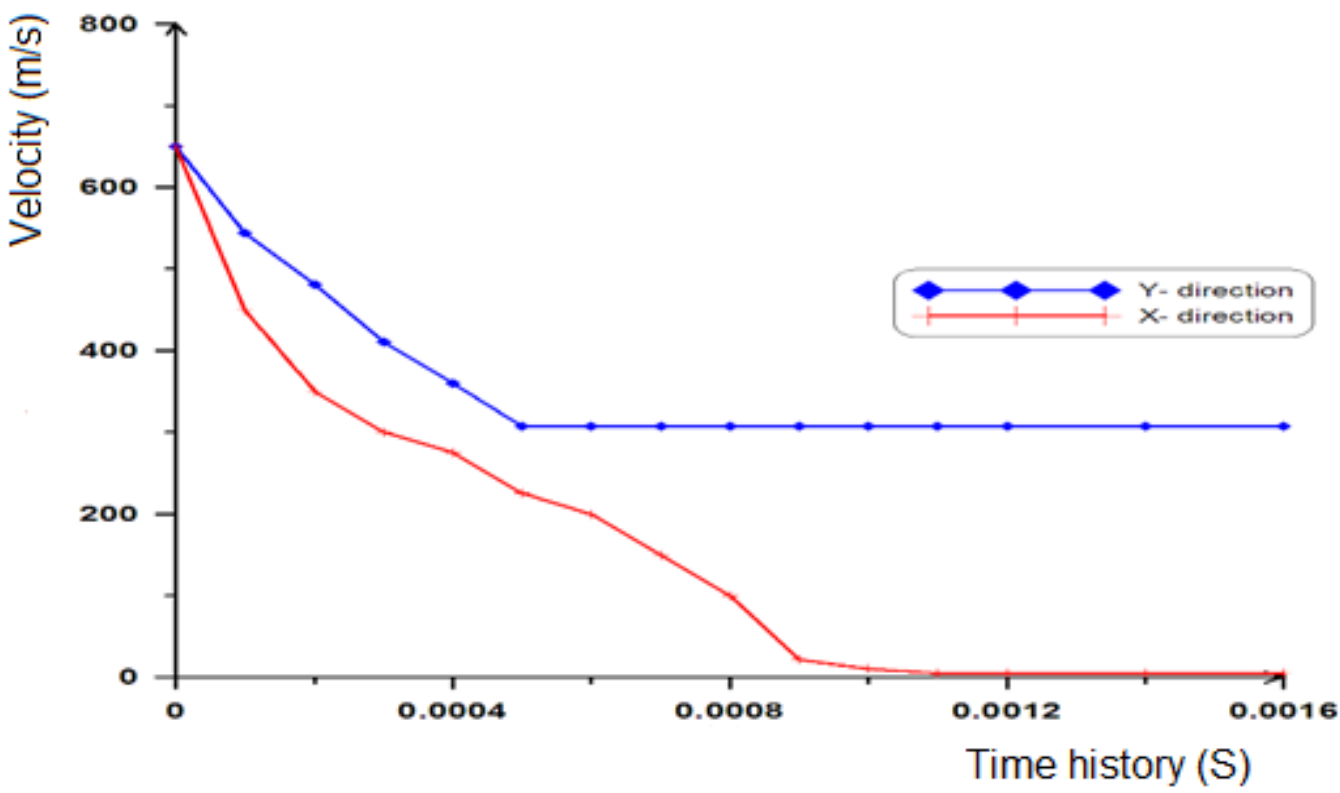

Figure (14). Comparison between the projectile velocities in $X \& Y$ directions, at $T_{d}=1$ $\mathrm{mm}, V_{i}=650 \mathrm{~m} / \mathrm{s}$. 